\title{
Aseptic Meningitis
}

National Cancer Institute

\section{Source}

National Cancer Institute. Aseptic Meningitis. NCI Thesaurus. Code C118299.

Inflammation of the membranes surrounding the brain and spinal cord without a bacterial pathogen. 